\title{
Parental alcohol abuse and eating behaviors in adolescents
}

\begin{abstract}
Introduction. Parental alcohol abuse hinders a child's development, which means that these children are more exposed to mental health problems.

Aim. The aim of this study was to analyze the link between the intensity of eating disorders in youngsters and family alcoholism.

Material and methods. The study was conducted among adolescents in the Lubelskie province. 1766 students, aged 12 to 22 were participants in the study. The authors used a method called Eating Disorder Inventory, as well as a self-designed questionnaire that included assessing the characteristics of every family.

Results. The findings of this study show that increased symptoms of eating disorders in children and teenagers correlates with alcohol dependency in the family. Adolescent children of alcoholics have higher levels of conflict identifying feelings and emotions (hunger, security) correctly. They were more likely to deem their actions as ineffective, as well as they were more frequently prone to binge eating than individuals who were not affected by drinking parents.

Conclusions. There is a need for some future work and preventive measures to be taken in families affected by problem drinking.
\end{abstract}

Keywords: parental alcoholism, eating disorders, adolescents.

DOI: $10.1515 /$ pjph-2015-0053

\section{INTRODUCTION}

Problem drinking parents have a tendency to act in an unpredictable way. Plus to that, parents drinking to excess are more likely to abuse their children, both physically and sexually. Borgart [1] and Bulik [2] regard family alcoholism as a potential risk factor for the development of eating disorders. Śmiarowska [3], in turn, notes that in families affected by anorexia nervosa parents' alcoholism occurred in $50 \%$ of the cases and family violence in $49.2 \%$ of the cases.

There are communication difficulties in families where substance abuse is an issue. Family life is characterized by chaos and unpredictability. Children tend to misunderstand parents' behaviors or moods, which may lead to their feeling confused and insecure and even lack of trust in parents. The youngsters may suffer from post-traumatic stress syndrome, with symptoms like sleep disorders or depression. They are more likely to have lowered self-esteem, anxiety and acting out behavior.

There is a hypothesis that alcohol abuse in a family significantly correlates with disordered eating attitudes and emotional consequences in secondary school students [4].

\section{AIM}

The objective of the paper was to verify this hypothesis.

\section{MATERIAL AND METHODS}

The research involved 1766 students, all aged 12-22. The authors excluded incorrectly completed questionnaires which meant that some 1675 questionnaires were left for an analysis. The study was conducted between October, 2004 and March, 2009 on youth students of the Textile School Complex (Zespót Szkót Wtókienniczych) and the Food Industry School Complex (Zespót Szkót Przemystu Spożywczego) in Lublin, the Construction School Complex (Zespót Szkót Budowlanych) in Biłgoraj, as well as junior high schools in Lublin Region. Students filled out questionnaires individually during homeroom classes. The participation was voluntary and students knew it was anonymous and used for scientific purposes.

In Poland, a general educational class, called sometimes form tutor period (godzina wychowawcza) is, in fact, a weekly special 45 minutes for a home teacher who decides about the topics to be talked about.

The following clinical tools were used: the Eating Disorders Inventory (EDI) which quantitatively assesses psychological cognitive constructs behind eating disorders; and a questionnaire

\footnotetext{
${ }^{1}$ Endocrynology and Child Diabetology Clinic, Children's University Hospital, Lublin, Poland

2 Department of Psychiatry, Psychotherapy and Early Intervention, Medical University of Lublin, Poland

${ }^{3}$ Dietetics Department of the University of Social Sciences, Lublin, Poland

${ }^{4}$ Department of Trauma Surgery and Emergency Medicine, Medical University of Lublin, Poland
} 
compiled by the authors, looking at selected social and clinical data.

\section{Own-invented scientific and research protocol}

A special questionnaire consisting of three parts was invented to collect clinical and socio-demographic data. Each part was preceded by instructions about how to choose answers. Respondents were advised that the study was anonymous and used for scientific purposes only. The first part included 21 questions looking at demographic data and basic information about each respondent. The second part was composed of 8 questions, containing data on the respondent's family and its internal relations.

\section{Eating Disorder Inventory}

The Polish version of the Eating Disorder Inventory was used to assess the level of specific cognitive disorders and behaviors related to eating disorders. It is a research tool created in Canada, based on a multidimensional conception of anorexia. The authors were D. M. Garner, M. P. Olmsted and J. Polivy [5]. The Polish adaptation and normalization of the questionnaire was conducted in the Psychiatry Clinic for Children and Adolescents of the Polish Institute of Psychiatry and Neurology.

The Eating Disorders Inventory is divided into 8 scales and for each the subject may choose one, out of six answers.

Three scales: Drive for Thinness (DT), Bulimia (B) and Body Dissatisfaction (BD) are used to quantitatively assess behavioral and cognitive patterns of anorexia and bulimia. The remaining five: Ineffectiveness (I), Perfectionism (P), Interpersonal Distrust (ID), Interoceptive Awareness (IA) and Maturity Fear (MF) are applied for a quantitative estimation of psychological constructs from which eating disorders stem.

The Mann-Whitney U test was used to analyze the significance of differences in two groups formed based on:

- alcohol dependency in the family:

no/yes

\section{RESULTS}

The information concerning alcohol abuse in respondents' families has been presented below.

TABLE 1. Numbers of groups formed based on the answer to the question: 'Has anybody from your immediate family been, or is, abusing, alcohol?' (no/yes).

\begin{tabular}{|c|c|c|}
\hline Group & Number of cases & $\%$ \\
\hline 'yes' & 1309 & $78.24 \%$ \\
\hline 'no’' & 364 & $21.76 \%$ \\
\hline
\end{tabular}

Some $21.76 \%$ of the researched students admitted they had or used to have a family member abusing alcohol.

Exacerbation of eating disorder symptoms and family alcoholism

In order to state whether there are differences in EDI test scales regarding answers to the question: 'Has anybody from your closest family been, or is, abusing, alcohol?' (no/yes) average values for particular EDI test scales have been calculated and the Mann-Whitney U difference significance test has been applied. Its results are shown in Tables 2 . and 3.
TABLE 2: Average EDI test scales results obtained by youth respondents who had a family member abusing alcohol and those who had not.

\begin{tabular}{lccc}
\hline \multirow{2}{*}{ EDI test scales } & Family alcoholism & Average & SD \\
\hline \multirow{2}{*}{ Drive for Thinness } & NO & 3.51 & 4.7 \\
\cline { 2 - 4 } & YES & 3.84 & 5.3 \\
\cline { 2 - 4 } & NO & 1.42 & 2.8 \\
\hline \multirow{2}{*}{ Body Dissatisfaction } & YES & 1.83 & 3.1 \\
\hline \multirow{2}{*}{ Ineffectiveness } & NO & 8.01 & 7.2 \\
\hline \multirow{2}{*}{ Perfectionism } & YES & 8.52 & 7.9 \\
\cline { 2 - 4 } & NO & 4.90 & 4.2 \\
\hline \multirow{2}{*}{ Interpersonal Distrust } & YES & 5.61 & 4.7 \\
\cline { 2 - 4 } & NO & 3.63 & 3.4 \\
\hline \multirow{2}{*}{ Interoceptive awareness } & YES & 3.72 & 3.5 \\
\cline { 2 - 4 } & NO & 4.33 & 3.6 \\
\hline \multirow{2}{*}{ Maturity Fear } & YES & 4.61 & 4.0 \\
\hline & NO & 4.14 & 4.3 \\
\cline { 2 - 4 } & YES & 5.13 & 4.5 \\
\hline
\end{tabular}

TABLE 3. Difference significance for EDI test scales regarding answers to the question: 'Has anybody from your closest family been, or is, abusing, alcohol?' (no/yes). Mann-Whitney U test results.

\begin{tabular}{lcc}
\hline \multicolumn{1}{c}{ EDI test scales } & $\mathrm{Z}$ & $\mathrm{p}$ \\
\hline Drive for Thinness & -0.348 & 0.728 \\
\hline Bulimia & -2.02 & 0.043 \\
\hline Body Dissatisfaction & -0.379 & 0.704 \\
\hline Ineffectiveness & -2.392 & 0.017 \\
\hline Perfectionism & -0.812 & 0.417 \\
\hline Interpersonal Distrust & -0.407 & 0.684 \\
\hline Interoceptive Awareness & -4.231 & 0.0001 \\
\hline Maturity Fear & -1.444 & 0.149 \\
\hline
\end{tabular}

The results presented above (Tables 2 and 3) suggest that unlike the individuals not having a problem drinker in the immediate family, children of alcoholics experienced greater difficulties recognizing their feelings and identifying them correctly. They feel less secure, while being more inclined to binge eating.

\section{DISCUSSION}

As opposed to those who are free of such burden, researched persons who experience family alcoholism had greater difficulty in identifying emotions accurately, stronger feeling of ineffectiveness and they are more inclined to binge eating. The results are similar to those by Kog and Vandereycken [6] who observed high alcoholism rate in extended families of subjects suffering from bulimia. Similarly, Vanderlinen [7] and Bulik [2] see family alcoholism as a potential risk factor of eating disorders. The findings of Garcia-Vilches et al. [8] seem interesting; they did not find any significant relations between a parent's alcohol abuse and the bulimia intensity.

Harris [9] makes an observation that experiencing traumatic family events is related to the fear of growing up. Individuals suffering from eating disorders are afraid of maturity. By resorting to the illness, they intend to prolong the dependence from others and delay the moment of assuming responsibility. 
Considering significant results of own-conducted research, corroborated by the collected literature on the subject, further studies need to be carried out; it is suggested that preventive measures are taken in families with substance abuse.

\section{CONCLUSIONS}

1. Subjects who experience family alcoholism had greater difficulty identifying feelings and emotions (hunger, security) correctly, stronger feeling of ineffectiveness and were more inclined to binge eating than persons who do not experience it.

2. Future work should explore the mechanisms of eating disorders in adolescents/young adults with family alcoholism and substance abuse.

\section{REFERENCES}

1. Borgart EJ, Meermann R. Stationare verhaltenstherapeutische Behandlung von Anorexie und Bulimie. In: M. Zielke. Angewandte Verhaltensmedizin in der Rehabilitation. Berlin: Pabst Science Publishers 2001; p. 275-307.

2. Bulik CM. Drug and alcohol abuse by bulimic women and their families. Am J Psychiatry. 1987;144:1604-6.

3. Śmiarowska M, Kamiński R, Mikołajczyk E, et al. Wpływ środowiska społecznego na nasilenie objawów jadłowstrętu psychicznego - badanie wstępne. Adv Clin Exp Med. 2006;15(1):89-95.

4. Schmidt U, Humfress H, Treasure J. The role of general family environment and sexual and physical abuse in the origins of eating disorders. Eur Eat Disord Rev. 1997;5(3):184-207.

5. Garner DM, Olmsted MP, Polivy J. The development and validation of a multidimensional Eating Disorder Inventory for anorexia nervosa and bulimia. Int J Eat Disord. 1983;2:15-34.

6. Kog E, Vandereycken W. Family characteristics of anorexia nervosa and bulimia: a review of the research literature. Clin Psychol Rev. 1985;5:15980 .

7. Vanderlinden J. Anorexia nervosa overwinnen. Tielt: Lannoo; 2002.

8. Garcia-Vilches I, Badia-Casanovas A, Fernandez-Aranda F, et al. Characteristics of bulimic patients whose parents do or do not abuse alcohol. Eat Weight Disord. 2002;7(3,23):2.

9. Harris M, Cumella EJ. Eating Disorders Across the Life Span. J Psychosoc Nurs Mental Health Servic. 2006;(44):4.

Corresponding author

Kinga Szymona

tel. 697-177-690

E-mail:kszymona@ahe.lodz.pl 